\title{
Role of Nitric Oxide and Peroxynitrite in the Cytokine-induced Sustained Myocardial Dysfunction in Dogs In Vivo
}

\author{
Jun-ichi Oyama, Hiroaki Shimokawa, Hidetoshi Momii, Xiao-shu Cheng, Naoto Fukuyama, ${ }^{*}$ Yukinori Arai, Kensuke Egashira, \\ Hiroe Nakazawa, ${ }^{*}$ and Akira Takeshita \\ The Research Institute of Angiocardiology and Cardiovascular Clinic, Kyushu University School of Medicine, Fukuoka, 812-8582 Japan; \\ and the *Department of Physiology, Tokai University School of Medicine, Isehara, 259-1193 Japan
}

\begin{abstract}
Studies in vitro suggested that inflammatory cytokines could cause myocardial dysfunction. However, the detailed mechanism for the cytokine-induced myocardial dysfunction in vivo remains to be examined. We thus examined this point in our new canine model in vivo, in which microspheres with and without IL-1 $\beta$ were injected into the left main coronary artery. Left ventricular ejection fraction (LVEF) was evaluated by echocardiography for $1 \mathrm{wk}$. Immediately after the microsphere injection, LVEF decreased to $\sim 30 \%$ in both groups. While LVEF rapidly normalized in $2 \mathrm{~d}$ in the control group, it was markedly impaired in the IL-1 $\beta$ group even at day 7 . Pretreatment with dexamethasone or with aminoguanidine, an inhibitor of inducible nitric oxide synthase, prevented the IL-1 $\beta$-induced myocardial dysfunction. Nitrotyrosine concentration, an in vivo marker of the peroxynitrite production by nitric oxide and superoxide anion, was significantly higher in the myocardium of the IL-1 $\beta$ group than in that of the control group or the group cotreated with dexamethasone or aminoguanidine. There was an inverse linear relationship between myocardial nitrotyrosine concentrations and LVEF. These results indicate that IL-1 $\beta$ induces sustained myocardial dysfunction in vivo and that nitric oxide produced by inducible nitric oxide synthase and the resultant formation of peroxynitrite are substantially involved in the pathogenesis of the cytokine-induced sustained myocardial dysfunction in vivo. (J. Clin. Invest. 1998. 101:2207-2214.) Key words: interleukin $1 \beta$ - cytokine $\cdot$ nitric oxide $\cdot$ peroxynitrite $\cdot$ cardiac dysfunction
\end{abstract}

\section{Introduction}

Inflammatory cytokines have been implicated to play an important role in the pathogenesis of inflammatory cardiovascu-

This work was presented in part at the annual scientific meeting of the American Heart Association in New Orleans, LA on 12 November 1996.

Address correspondence to Dr. Hiroaki Shimokawa, The Research Institute of Angiocardiology and Cardiovascular Clinic, $\mathrm{Ky}-$ ushu University School of Medicine, 3-1-1 Maidashi, Higashi-ku, Fukuoka, 812-8582 Japan. Phone: 81-92-642-5360; FAX: 81-92-6425374; E-mail: shimo@cardiol.med.kyushu-u.ac.jp

Received for publication 20 June 1997 and accepted in revised form 3 March 1998.

J. Clin. Invest.

(C) The American Society for Clinical Investigation, Inc. 0021-9738/98/05/2207/08 \$2.00

Volume 101, Number 10, May 1998, 2207-2214

http://www.jci.org lar diseases, including acute myocarditis $(1,2)$, heart failure (1, 2 ), allograft rejection (3), and atherosclerosis (4-6). Previous studies demonstrated that IL-1 $\beta$, one of the major inflammatory cytokines (4-6), acutely reduced the contraction of ferret papillary muscle and of rat myocytes in vitro (7), and acutely caused hypotension in rabbits in vivo (8). The plasma levels of IL-1 $\beta$ correlate with the extent of congestive heart failure in mice inoculated with encephalomyocarditis virus (9). TNF- $\alpha$, another major inflammatory cytokine (4-6), also exerts negative inotropic effects in hamster papillary muscles (10), and its plasma and myocardial levels are increased in patients with chronic heart failure $(11,12)$. In patients with septic shock, several cytokines, including IL- $1 \beta$ and TNF- $\alpha$, are present in the serum (13). IL-1 $\beta$ is a pleiotropic cytokine, and is also known as a potent inducer for inducible nitric oxide synthase $(\text { iNOS })^{1}$ (14-16). However, since a suitable in vivo model of cytokine-induced myocardial dysfunction has not been available, the detailed mechanism for the cytokine-induced myocardial dysfunction in vivo remains unknown.

Thus, the aim of this study was to elucidate the mechanisms of the cytokine-induced myocardial dysfunction in vivo. To achieve this, we developed a new canine model of cytokineinduced myocardial dysfunction in which we introduced IL-1 $\beta$ to the whole left ventricle by injecting IL-1 $\beta$-bound microspheres (MS).

\section{Methods}

Animal preparation. This study was reviewed and approved by the Committee of the Ethics on Animal Experiments and carried out under the Guidelines for Animal Experiments at the Kyushu University School of Medicine and according to Law 105 and Notification 6 of the Japanese Government. Adult mongrel dogs weighing 9-18 kg were sedated with ketamine hydrochloride $(10 \mathrm{mg} / \mathrm{kg}$ intramuscularly) and anesthetized with sodium pentobarbital $(25 \mathrm{mg} / \mathrm{kg}$ intravenously). The animal was intubated and mechanically ventilated with room air mixed with oxygen in the supine position. Lactated Ringer solution was administered intravenously at a rate of $5 \mathrm{ml} / \mathrm{kg} / \mathrm{h}$ to compensate for evaporative fluid losses. A fluid-filled catheter connected to the pressure transducer was advanced into the left ventricle via the left carotid artery for continuous measurement of BP, heart rate, and left ventricular end-diastolic pressure (LVEDP). The jugular vein was also cannulated for intravenous administration of drugs and blood sampling.

Preparation of IL-1 $\beta$-bound MS. $10^{8}$ colored MS $(15 \mu \mathrm{m}$ in diameter) (E-Z Trak Co., Los Angeles, CA), which bind the amino res-

\footnotetext{
1. Abbreviations used in this paper: $\mathrm{CPK}-\mathrm{MB}$, creatinine phosphokinase; eNOS, endothelial nitric oxide synthase; iNOS, inducible nitric oxide synthase; LAD, left anterior descending coronary artery; LCX, left circumflex coronary artery; LVEDP, left ventricular enddiastolic pressure; LVEF, left ventricular ejection fraction; MPO, myeloperoxidase; MS, microspheres.
} 
idues of proteins (such as cytokines), were centrifuged at 3,000 rpm for $5 \mathrm{~min}$. After the supernatant was separated, MS were added to 5 $\mathrm{ml}$ of $80 \%$ ethanol and suspended in $2 \mathrm{ml}$ of $5 \mathrm{M} \mathrm{NaOH}$ solution for 5 $\mathrm{min}$. After centrifugation at 3,000 rpm for $5 \mathrm{~min}$, the above procedure was repeated twice. MS were added to $5 \mathrm{ml}$ of $80 \%$ ethanol and resuspended in $2 \mathrm{ml}$ of $1 \mathrm{M}$ Tris solution for $5 \mathrm{~min}$. After centrifugation at 3,000 rpm for $5 \mathrm{~min}$, the above procedure was repeated twice. After the addition of $5 \mathrm{ml}$ of $80 \%$ ethanol, MS were resuspended in $2 \mathrm{ml}$ of $0.1 \mathrm{M} \mathrm{NaHCO}_{3}$ solution for $5 \mathrm{~min}$. After centrifugation at 3,000 rpm for $5 \mathrm{~min}$, MS were resuspended in $2 \mathrm{ml}$ of $0.1 \mathrm{M} \mathrm{NaHCO}_{3}$ solution with $0.1 \mathrm{mg}$ of human recombinant IL-1 $\beta$. MS were allowed to bind with IL-1 $\beta$ at room temperature overnight. The IL-1 $\beta$-bound MS were resuspended with $0.2 \mathrm{ml}$ of canine serum for $2 \mathrm{~h}$ to coat their remaining surface to avoid any nonspecific adsorption. The control MS were also coated in a similar manner with canine serum so that they would not cause any nonspecific effects. The IL-1 $\beta$-bound MS and the control MS were washed and resuspended at $4^{\circ} \mathrm{C}$. The molecules of IL- $1 \beta$ were thus connected to the surface of the MS and the final concentration of IL- $1 \beta$ was $\sim 1 \mu \mathrm{g} / 10^{6} \mathrm{MS} / \mathrm{ml}$. In some experiments, the IL-1 $\beta$-bound MS were additionally treated in advance with neutralizing antibody to human IL- $1 \beta$ at a concentration of 0.1 $\mathrm{mg} / 10^{6} \mathrm{MS} / \mathrm{ml}$ (100 times higher than the concentration of IL-1 $\beta$ ) at room temperature overnight. All of the above preparations were performed under sterile conditions.

Experimental protocols. We first attempted to develop a canine model of cytokine-induced myocardial dysfunction in vivo. A Kifer coronary catheter was inserted into the left main coronary artery via the right carotid artery, and IL- $1 \beta-$ bound MS (IL- $1 \beta$ group) or control MS (control group) were injected into the left coronary arteries under fluoroscopy at a dose of $10^{6} \mathrm{MS} / \mathrm{kg}$, that is $1 \mu \mathrm{g} \mathrm{IL}-1 \beta / \mathrm{kg}$. In a preliminary study, we confirmed that IL- $1 \beta$ bound to MS remained in the myocardium by $>70 \% 1 \mathrm{wk}$ after the IL- $1 \beta$-bound MS injection (measured by ELISA).

We first examined the inhibitory effects of neutralizing antibody to human IL-1 $\beta$ by injecting MS bound with IL-1 $\beta$ plus the antibody. We then examined the possible inhibitory effect of glucocorticoid and of the inhibition of iNOS on the IL- $1 \beta$-induced myocardial dysfunction. We intravenously administered dexamethasone $(3 \mathrm{mg} / \mathrm{kg}) 1 \mathrm{~h}$ before MS injection and continuously infused it at a dose of $0.5 \mathrm{mg} /$ $\mathrm{kg} / \mathrm{h}$ until day 2 . We also examined the effect of aminoguanidine, a relatively selective inhibitor of iNOS $(17,18)$, which was intravenously administered at a dose of $100 \mathrm{mg} / \mathrm{kg}$ before MS injection and thereafter continuously infused at a dose of $10 \mathrm{mg} / \mathrm{kg} / \mathrm{h}$ until day 2 . In a preliminary study, we confirmed that the dose of aminoguanidine used does not inhibit the endothelial NOS (eNOS) activity as it did not affect the responses of coronary blood flow to intracoronary acetylcholine or of systemic BP to intravenous acetylcholine (data not shown).

On day 2 or day 7, the animals were again anesthetized and ventilated as described above, and heart rate, aortic pressure, and LVEDP were evaluated. After the hemodynamic evaluation, animals were killed by an overdose of intravenous pentobarbital, and the myocardium was immediately obtained and frozen at $-80^{\circ} \mathrm{C}$ for the measurements of nitrotyrosine concentrations and myeloperoxidase (MPO) activity.

Follow-up of left ventricular function by echocardiography. Left ventricular ejection fraction (LVEF) was evaluated by echocardiography using an echocardiogram (model SSH-65A; Toshiba Medical Co., Tokyo, Japan) on the experimental day under conscious conditions before MS injection and under anesthesia after MS injection, and thereafter under conscious conditions on days 1,2, 4, and 7. Short axis view of the left ventricle at the papillary muscle level was used to obtain LVEF.

Measurement of white blood cell counts and creatinine phosphokinase $(C P K-M B)$ values. White blood cell count in the peripheral venous blood was determined (Sysmex SE-9000; Toa Medical Electronics Co., Ltd., Kobe, Japan). Serum levels of CPK-MB were determined by chemiluminescent immunoassay.

Histological examination. On day 2 or day 7, the animals were killed by intravenous injection of an excess dose of sodium pentobarbital. The heart was quickly removed, flash frozen in liquid nitrogen, and then stored at $-80^{\circ} \mathrm{C}$ for later analysis. The rest was fixed with $6 \%$ formalin for at least $24 \mathrm{~h}$. The heart was sliced into transverse sections. Histological samples were taken from each section and stained with hematoxylin-eosin.

Measurement of myocardial MPO activity. As a specific enzymatic marker of neutrophil infiltration into the myocardium, myocardial MPO activity was determined in myocardial tissue, using a method similar to that described by Bradley et al. (19). Briefly, frozen myocardial tissue samples were homogenized in $1 \mathrm{ml}$ of $50 \mathrm{mM}$ potassium phosphate buffer at $\mathrm{pH} 6.0$, containing $0.5 \%$ hexadecyltrimethyl ammonium bromide, using a Polytron tissue homogenizer (model CH6005; KINEMATICA, Luzern, Switzerland) for $10 \mathrm{~s}$ four times at $7,000 \mathrm{rpm}$. The homogenized solutions were freeze-thawed three times and sonicated twice to disrupt the cells, and centrifuged at $4^{\circ} \mathrm{C}$ for $30 \mathrm{~min}$ at $15,000 \mathrm{rpm}$. MPO activity in the supernatant was assayed by measuring the change in absorbance $(490 \mathrm{~nm})$ resulting from decomposition of $\mathrm{H}_{2} \mathrm{O}_{2}$. In the presence of $o$-phenylene-diamine, MPO activity was normalized using human MPO as a standard (20).

Measurement of myocardial nitrotyrosine concentrations. Under circumstances where both NO and superoxide are cogenerated, they react with each other and yield the harmful radical peroxynitrite (21), which has a very short half-life ( $\sim 1.9 \mathrm{~s}$ at $\mathrm{pH} 7.4)(22)$. However, peroxynitrite reacts with L-tyrosine to produce nitrotyrosine, which is a stable substance and can be used as an in vivo marker of peroxynitrite formation $(23,24)$. Thus, we measured myocardial concentrations of nitrotyrosine in this study. Frozen myocardium was homogenized with $500 \mu \mathrm{l}$ milli-Q water and hydrolyzed as reported previously (25). Separation of nitrotyrosine was achieved via HPLC using a 5- $\mu$ C-18 reverse-phase column $(15 \mathrm{~cm} \times 4.6 \mathrm{~mm})$ (Nucleocil; Nihon Bunko,

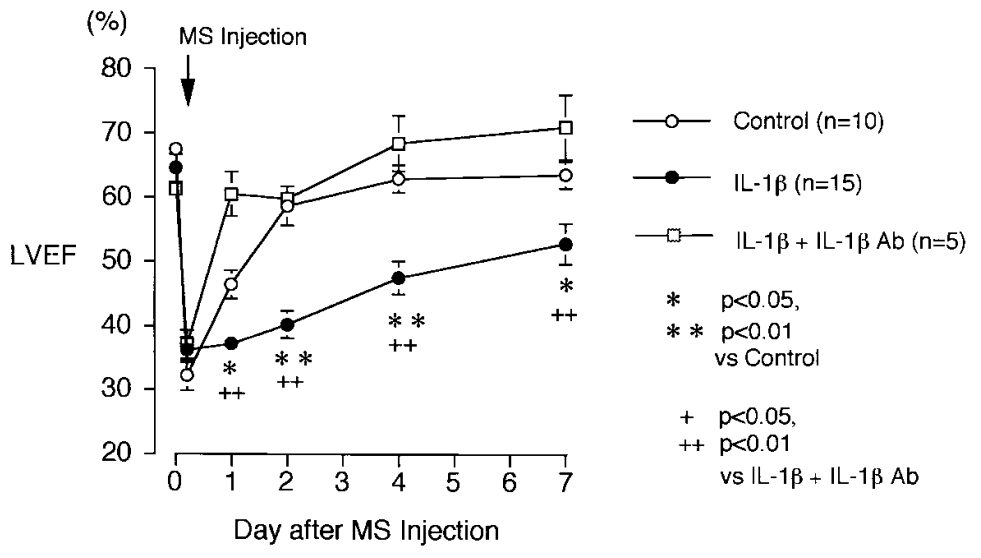

Figure 1. Time course of LVEF assessed by echocardiography in the control group (Control), the IL-1 $\beta$ group $(I L-1 \beta)$, and the group treated with MS bound with IL-1 $\beta$ plus neutralizing antibody to IL-1 $\beta(I L-1 \beta+I L-1 \beta A b)$. Results are presented as mean \pm SEM. MS injection, Intracoronary injection of MS. 
Table I. Hemodynamic Variables

\begin{tabular}{lrlll}
\hline & & HR & mAoP & LVEDP \\
\hline & $n$ & min & $m m H g$ & $m m H g$ \\
IL-1 $\beta$ group & & & & \\
$\quad$ Before MS injection & 14 & $187 \pm 10$ & $144 \pm 8$ & $2 \pm 1$ \\
After MS injection & 14 & $152 \pm 9^{\S}$ & $108 \pm 7^{\S}$ & $8 \pm 2^{\S}$ \\
Day 2 & 6 & $158 \pm 11^{\ddagger}$ & $101 \pm 10^{\ddagger}$ & $6 \pm 2^{* \ddagger}$ \\
Day 7 & 8 & $164 \pm 9$ & $103 \pm 15^{\ddagger}$ & $6 \pm 3$ \\
Control group & & & & \\
$\quad$ Before MS injection & 8 & $170 \pm 11$ & $125 \pm 9$ & $1 \pm 1$ \\
After MS injection & 8 & $149 \pm 13$ & $109 \pm 8$ & $5 \pm 1^{\ddagger}$ \\
Day 2 & 5 & $158 \pm 10$ & $101 \pm 6$ & $1 \pm 0$ \\
Day 7 & 6 & $162 \pm 5$ & $110 \pm 10$ & $2 \pm 1$ \\
& & & & \\
\hline
\end{tabular}

Results are expressed as mean \pm SEM. $H R$, Heart rate; and $m A o P$, mean aortic pressure. ${ }^{*} P<0.05$ vs. control group. ${ }^{\ddagger} P<0.05$, and ${ }^{\S} P<$ 0.01 vs. values of variables before MS injection in the same group.

Tokyo, Japan) with a guard column (JASCO Ltd., Tokyo, Japan). The column was eluted with $50 \mathrm{mM} \mathrm{KH} \mathrm{PO}_{4}-\mathrm{H}_{3} \mathrm{PO}_{4}(\mathrm{pH} \mathrm{3.0)}$ with $10 \%$ methanol (vol/vol) at a flow rate of $1 \mathrm{ml} / \mathrm{min}$ through an isocratic pump and peaks were measured with an ultraviolet detector set at $274 \mathrm{~nm}$ (JASCO Ltd.). The nitrotyrosine peak was identified on the basis of the retention time of authentic nitrotyrosine and conversion of the peak to aminotyrosine when it was reduced by excess hydrosulfate. The detection limit was $0.6 \mu \mathrm{M}$ in this setting. Nitrotyrosine concentration was expressed as a percentage of total tyrosine concentration.

Statistical analysis. Results are presented as mean \pm SEM. Regarding the MPO activity and nitrotyrosine concentrations, the mean values in the myocardium perfused by the left anterior descending (LAD) and circumflex coronary arteries (LCX) were used.

To analyze the time course of LVEF and of other variables, we first tested the differences in the entire time course with an ANOVA for repeated measures, and if a significant difference was noted, posthoc comparison by Fisher's test was performed to compare the variable at each time point. $P<0.05$ was regarded to be statistically significant.

\section{Results}

Effect of IL-1 $\beta$-bound MS. Fig. 1 shows the time course of LVEF in the IL-1 $\beta$ and the control groups. The intracoronary injection of IL-1 $\beta$-bound MS or control MS acutely caused a comparable degree of decrease in LVEF. While LVEF in the control group rapidly recovered to the control levels within $2 \mathrm{~d}$, it remained decreased in the IL-1 $1 \beta$ group until day 7 although it tended to be improved after day 2 (Fig. 1). The cotreatment with IL-1 $\beta$ plus neutralizing antibody to IL- $1 \beta$ prevented the IL-1 $\beta$-induced sustained myocardial dysfunction (Fig. 1).

Heart rate or mean aortic pressure tended to be decreased during the experimental period in both groups; however, no difference in the values was noted between the two groups at any time (Table I). In contrast, LVEDP was significantly elevated in the IL-1 $\beta$ group as compared with the control group on day 2 (Table I).

Table II shows the time course of peripheral white blood cell counts and of CPK-MB values. White blood cell counts were significantly increased from baseline levels in both groups, and the extent of the increase was greater in the IL-1 $\beta$ group than in the control group on day 2. CPK-MB values were also increased in both groups from immediately after the MS injection to day 2, but there was no significant difference in the increase between the two groups.

Histological findings. Infiltration of polymorphonuclear cells (most of them were neutrophils) into the myocardium was noted around the MS on day 2, and the extent of the infiltration was more prominent in the IL-1 $\beta$ group than in the control group (Fig. 2).

Myocardial MPO activity. There was no statistical difference in the MPO activity between the myocardium perfused by LAD and that by LCX (data not shown). Myocardial MPO activity was significantly higher in the IL-1 $\beta$ group than in the control group on day 2 (Fig. 3). MPO activity then decreased in both groups, and there was no difference in the activity on day 7 between the two groups (Fig. 3).

Effect of dexamethasone and aminoguanidine. Administration of dexamethasone or aminoguanidine $1 \mathrm{~h}$ before MS injection did not alter systemic arterial pressure, heart rate, or LVEDP (data not shown). Dexamethasone prevented the IL$1 \beta$-induced myocardial dysfunction $(P<0.0001$ vs. IL-1 $\beta$ group by ANOVA) (Fig. 4). Similarly, aminoguanidine markedly inhibited the IL-1 $\beta$-induced myocardial dysfunction $(P<$ 0.0001 vs. IL-1 $1 \beta$ group by ANOVA) (Fig. 5). In contrast, dexamethasone or aminoguanidine did not alter the time course of LVEF in the control group ( $n=3$ each, data not shown).

Myocardial concentrations of nitrotyrosine. There was not a statistically significant difference in the myocardial concen-

Table II. Time Course of Peripheral Venous WBC Counts and CPK-MB Levels

\begin{tabular}{|c|c|c|c|c|c|c|c|}
\hline & & Before MS injection & After MS injection & Day 1 & Day 2 & Day 4 & Day 7 \\
\hline & $n$ & & & & & & \\
\hline \multicolumn{8}{|c|}{$\mathrm{WBC}\left(\times 10^{3} / \mu \mathrm{l}\right)$} \\
\hline Control & 6 & $5.4 \pm 0.8$ & $6.6 \pm 2.0$ & $27.2 \pm 5.4^{\S}$ & $18.4 \pm 2.9^{\S}$ & $21.1 \pm 2.8^{\S}$ & $22.9 \pm 4.0^{\S}$ \\
\hline IL-1 $\beta$ & 10 & $9.1 \pm 1.1$ & $6.8 \pm 1.5$ & $36.8 \pm 3.8^{\S}$ & $30.6 \pm 2.2 * \S$ & $21.6 \pm 3.0^{\S}$ & $27.4 \pm 6.1^{\S}$ \\
\hline \multicolumn{8}{|c|}{ CPK-MB (IU/ml) } \\
\hline Control & 8 & $3 \pm 1$ & $8 \pm 1^{\ddagger}$ & $107 \pm 24^{\S}$ & $11 \pm 2^{\ddagger}$ & $5 \pm 1$ & $3 \pm 0$ \\
\hline IL-1 $\beta$ & 8 & $3 \pm 0$ & $8 \pm 3^{+}$ & $67 \pm 14^{\S}$ & $11 \pm 2 \ddagger$ & $3 \pm 0$ & $2 \pm 0$ \\
\hline
\end{tabular}

Results are expressed as mean \pm SEM. $W B C$, white blood cells; and $C P K$, creatinine phosphokinase. ${ }^{*} P<0.05$ vs. control. ${ }^{\ddagger} P<0.05$, and ${ }^{\S} P<0.01$ vs. values of variables before MS injection in the same group. 


\section{IL-1 $\beta$ Group}
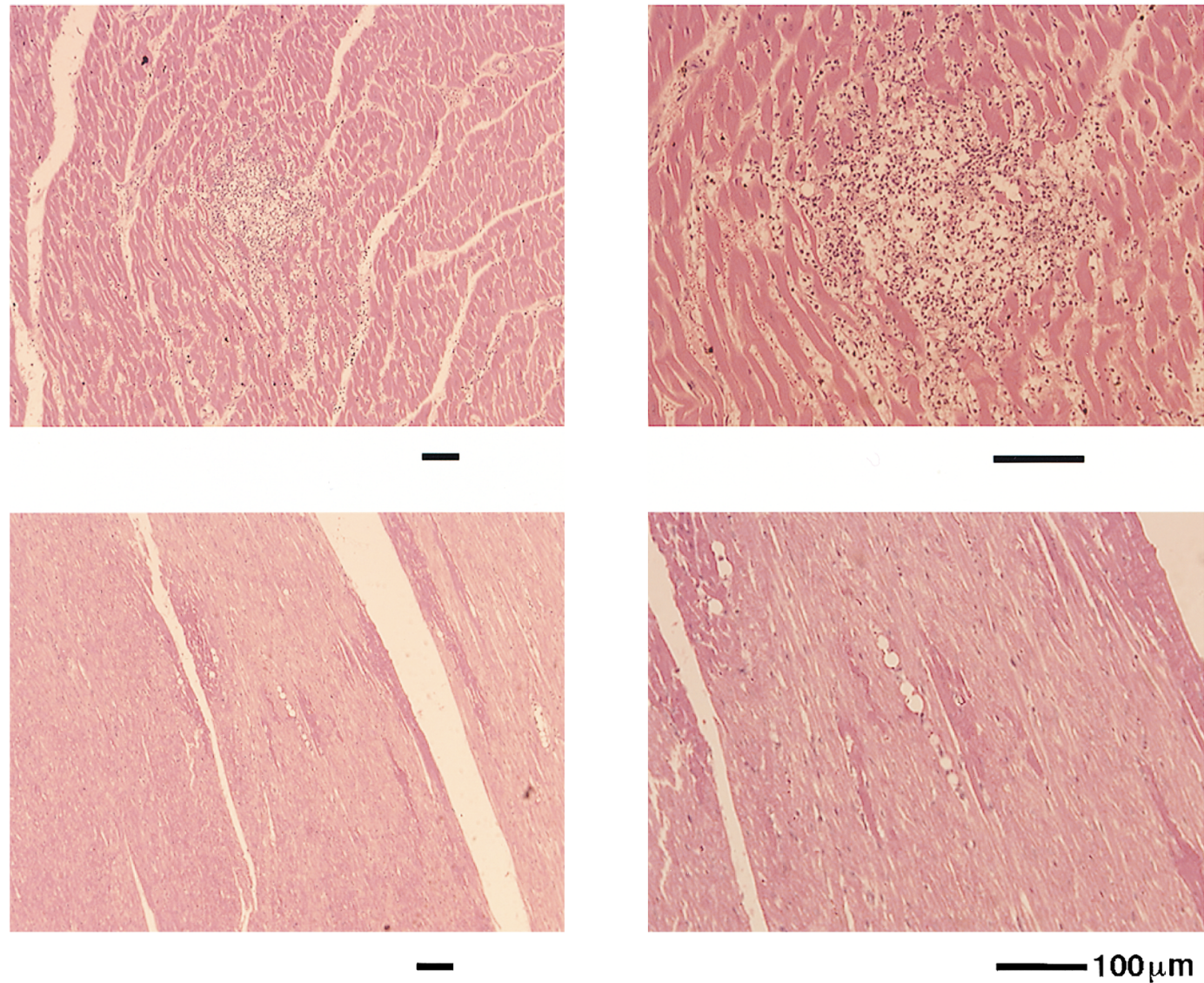

Figure 2. Histological findings (hematoxylin-eosin staining) of the myocardium in the control and the IL-1 $\beta$ group on day 2 after MS injection. Marked infiltration of neutrophils was noted in the IL- $1 \beta$ group but not in the control group. Embolized MS can be seen as white spots.

trations of nitrotyrosine between the myocardium perfused by LAD and that by LCX (data not shown). Myocardial nitrotyrosine concentrations were significantly higher in the IL-1 $\beta$ group than in the control group on both day 2 and day 7 (Fig. $6)$. The treatment with dexamethasone or aminoguanidine

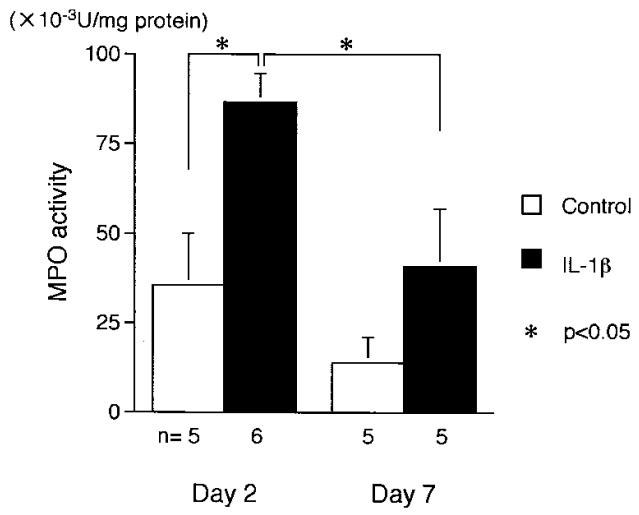

Figure 3. Myocardial MPO activity in the control and the IL-1 $\beta$ groups on days 2 and 7 after MS injection. Results are presented as mean \pm SEM. Control, Animals that received control MS; and $I L-1 \beta$, animals that received IL- $1 \beta$-bound MS. prevented the IL-1 $\beta$-induced tyrosine nitration determined on day 7 (Fig. 6).

Nitrotyrosine is a stable substance $(23,24)$. In this study, there was no significant increase in the myocardial nitrotyrosine concentrations from day 2 to day 7 , which suggests that during this period either no significant amount of nitrotyrosine was formed or at least no significant increase in myocardial nitrotyrosine occurred. Thus, in animals that were followed-up until day 7, their LVEF on day 2 was analyzed with their nitrotyrosine concentrations on day 7 . The analysis showed that there was a significant negative linear relationship between myocardial nitrotyrosine concentrations and LVEF on day 2 (Fig. 7).

\section{Discussion}

The major findings of this study were: $(a)$ chronic treatment with IL-1 $\beta$ caused sustained myocardial dysfunction in vivo, (b) the IL-1 $\beta$-induced sustained myocardial dysfunction was associated with increased production of peroxynitrite, and (c) dexamethasone or aminoguanidine exerted inhibitory effects on both the IL-1 $\beta$-induced sustained myocardial dysfunction and the peroxynitrite formation in vivo.

A canine model of cytokine-induced myocardial dysfunction in vivo. Inflammatory cytokines have been implicated to 


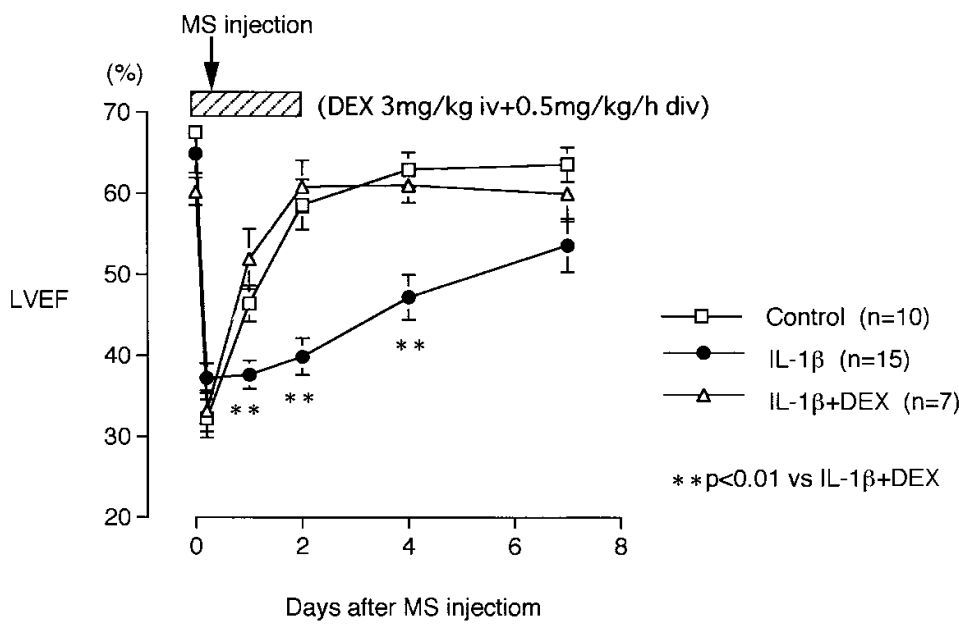

Figure 4. Inhibitory effect of dexamethasone $(D E X)$ on the IL-1 $\beta$-induced sustained myocardial dysfunction in vivo. Results are presented as mean \pm SEM. MS injection, Intracoronary injection of MS, Control, animals that received control MS; $I L-1 \beta$, animals that received IL-1 $1 \beta$-bound MS; and $I L-1 \beta+D E X$, animals that received IL-1 $\beta$-bound MS plus treatment with dexamethasone. play an important role in the pathogenesis of a wide variety of inflammatory cardiovascular diseases (1-6). In sepsis, inflammatory cytokines may cause hypotension and myocardial dysfunction, leading to multiple organ failure and death (26). However, since cardiac preload and afterload are also decreased in sepsis, it is difficult to discriminate the cardiac effects of the cytokines from their systemic effects in vivo.

Thus, we developed an animal model in which IL-1 $\beta$-bound MS affected the heart alone without causing any systemic effect. We were able to demonstrate that IL- $1 \beta$ triggers sustained myocardial dysfunction in vivo when applied selectively and chronically to the heart. The inhibitory effect of the neutralizing antibody to IL- $1 \beta$ confirmed that the sustained myocardial dysfunction in the IL-1 $\beta$ group was, indeed, triggered by the cytokine. However, since IL-1 $\beta$ is bound to MS and does not directly affect the myocardium, we think that IL-1 $\beta$ bound to MS triggered the local inflammatory responses at coronary microvessel levels, leading to the activation of the endogenous cytokine network in the heart, where NO and super-

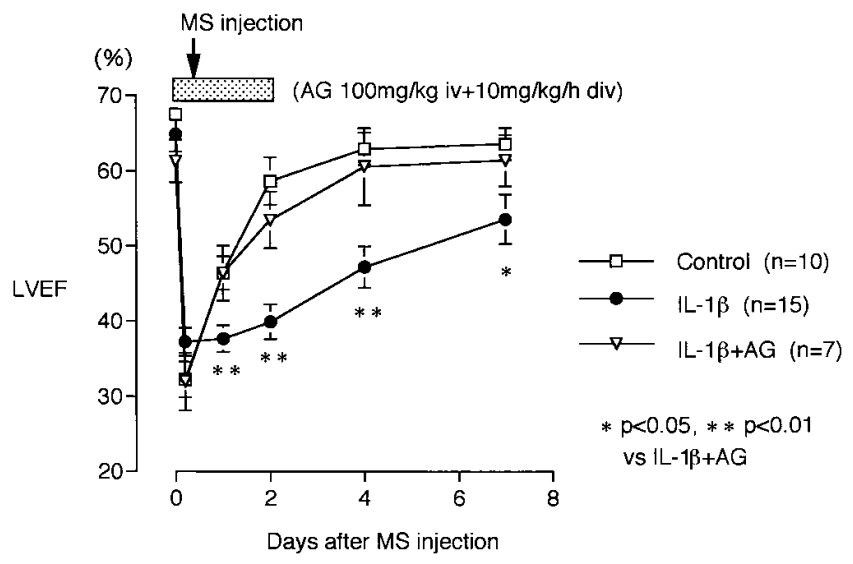

Figure 5. Inhibitory effects of aminoguanidine $(A G)$ on the IL-1 $\beta-$ induced sustained myocardial dysfunction in vivo. Results are presented as mean \pm SEM. MS injection, Intracoronary injection of MS; Control, animals that received control MS; $I L-1 \beta$, animals that received IL-1 $\beta$-bound MS; and $I L-1 \beta+A G$, animals that received IL-1 $\beta$-bound MS plus treatment with aminoguanidine. oxide are coproduced by various cells in the heart, including endothelial cells, vascular smooth muscle cells, infiltrating inflammatory cells, and cardiac myocytes.

We have observed recently that the inhibition of the infiltration of inflammatory cells into the myocardium by inhibitors of adhesion molecules (27) or the inhibition of superoxide anion production by a specific inhibitor (28) also prevents the IL-1 $\beta$-triggered sustained myocardial dysfunction with an abolishment of peroxynitrite formation. Taken together with the observed results, these findings characterized our in vivo model. That is, IL-1 $\beta$ bound to MS (but not MS, per se) causes local inflammatory reactions at the coronary microvessel level, where infiltration of inflammatory cells is augmented due to the upregulation of adhesion molecules (27). As a result, the endogenous cytokine network is activated, various types of cells in the heart produce NO and superoxide anion (28) which

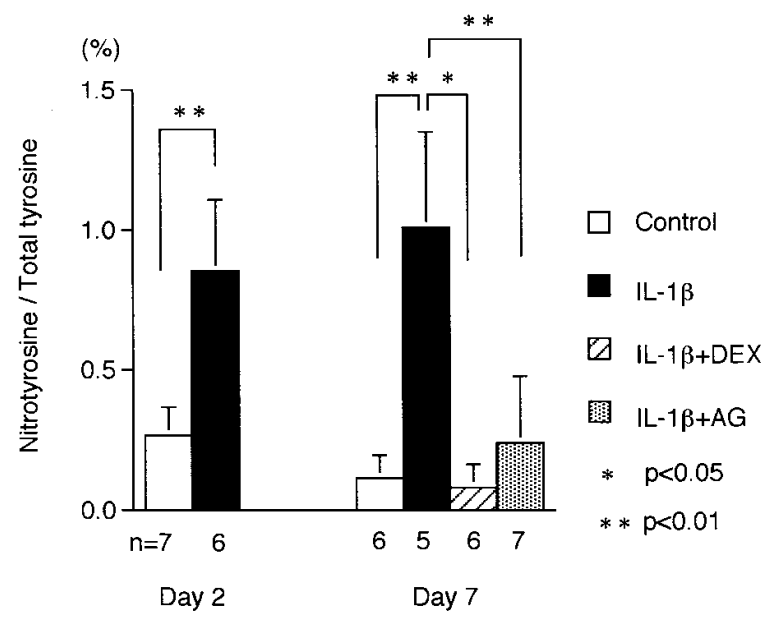

Figure 6. Myocardial nitrotyrosine concentrations measured by an HPLC assay. Vertical axis shows the ratio (\%) of nitrotyrosine to total tyrosine in the myocardium on days 2 and 7 after MS injection. Results are presented as mean \pm SEM. Control, Animals that received control MS; $I L-1 \beta$, animals that received IL-1 $\beta-$ bound MS; $I L-1 \beta+$ $D E X$, animals that received IL- $1 \beta$-bound MS plus treatment with dexamethasone; and $I L-1 \beta+A G$, animals that received IL-1 $\beta-$ bound MS plus treatment with aminoguanidine. 


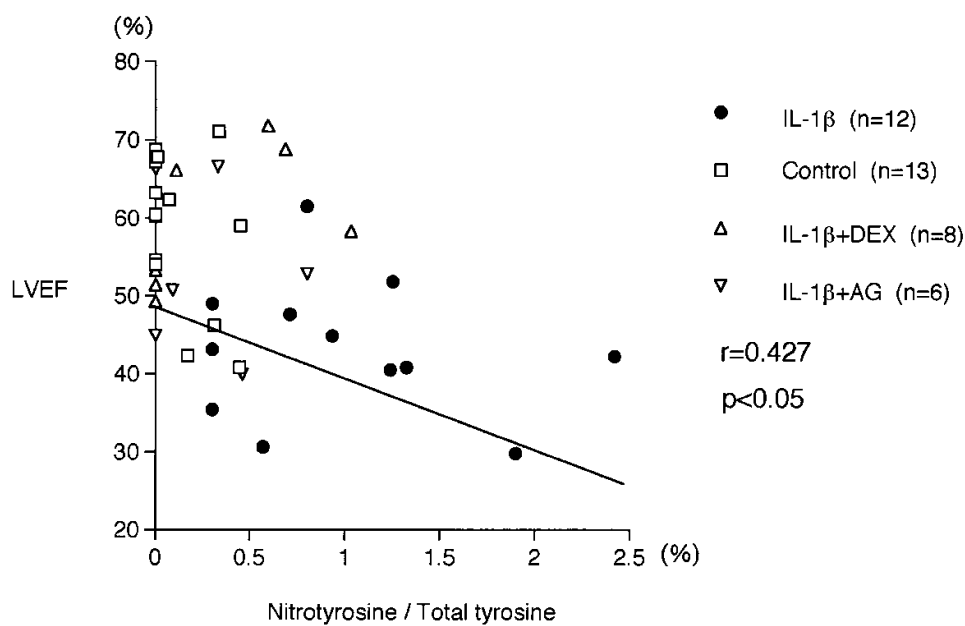

Figure 7. An inverse linear relationship between myocardial nitrotyrosine levels and LVEF. Results are presented as mean \pm SEM. Control, animals that received control MS; $I L-1 \beta$, animals that received IL- $1 \beta-$ bound MS; $I L-1 \beta+$ $D E X$, animals that received IL-1 $\beta$-bound MS plus treatment with dexamethasone; and $I L-1 \beta+A G$, animals that received IL-1 $\beta$-bound MS plus treatment with aminoguanidine. leads to the formation of peroxynitrite, a harmful radical, and the resultant myocardial dysfunction. Thus, the myocardial dysfunction in our model appears to consist of several cascades of inflammatory responses in the heart in vivo.

Role of NO in the cytokine-induced myocardial dysfunction in vivo. At present, no specific antibody or cDNA probe is available to detect canine iNOS. We tested all eight of the currently available antibodies to iNOS (for immunohistochemistry) and three cDNAs to the enzyme (for Northern blot); however, due to species differences, we were unable to detect any iNOS expression in the present canine model. Notably iNOS was also undetectable in dogs treated with lipopolysaccharide.

Alternatively, in a separate experiment, we attempted to demonstrate the iNOS expression in the heart of rats that were treated with IL-1 $\beta$ MS in a similar manner as in this study (instead of selective intracoronary injection in dogs, IL-1 $\beta$ MS were injected into the aortic cusp in rats while occluding the ascending aorta by balloon inflation under the guidance of fluoroscopy). In this separate experiment, we were able to demonstrate the induction of iNOS mRNA (by RT-PCR) and the iNOS immunoreactivity (by immunostaining) in the IL-1 $\beta-$ treated rat heart (data not shown). The immunoreactivity of iNOS was noted in endothelial cells, vascular smooth muscle cells, and infiltrating inflammatory cells, and to a lesser extent, in cardiac myocytes and other types of cells, in the IL-1 $\beta-$ treated rat heart (data not shown). Thus, it is reasonable to assume that iNOS was also induced in the canine heart in vivo in this study. Those findings are consistent with the previous reports of the cytokine-induced iNOS induction and resultant production of a large amount of NO in a wide variety of cardiac tissues, including endothelial cells (29), neutrophils (30), macrophages (31), fibroblasts (32), vascular smooth muscle cells (33), and cardiac myocytes (14-16).

Overproduction of NO by iNOS attenuates myocardial shortening and $\beta$-adrenergic response in vitro in animal models of septic shock and chronic heart failure (33-35). In this study, dexamethasone (which nonspecifically inhibits the synthesis of proteins including iNOS) $(14,15)$ and aminoguanidine (a relatively selective inhibitor of iNOS) $(17,18)$ both prevented the IL-1 $\beta$-induced sustained myocardial dysfunction in vivo. These results indicate that NO produced by iNOS plays an important role in the pathogenesis of the cytokineinduced myocardial dysfunction in our model in vivo.

Inhibition by L-arginine analogues of NO production has been shown to partially ameliorate myocardial dysfunction in endotoxemia (36). In a preliminary study, we tested the ability of $N^{\omega}$-nitro-L-arginine (L-NAME), a nonspecific inhibitor of both constitutive NOS and iNOS, to inhibit NO production in vivo, at a low dose that did not affect the systemic hemodynamics. However, LVEF progressively worsened by the L-arginine analogue infusion alone, even before the IL-1 $\beta$ MS administration. Although the reason for this adverse effect of $N^{\omega}$-nitro-L-arginine in vivo was unknown, it is possible that the L-arginine analogue impaired the perfusion of the heart by inhibiting eNOS even if the systemic pressure remained unchanged. Alternatively, we used aminoguanidine, a relatively selective inhibitor of iNOS $(17,18)$, and were able to prevent the cytokine-induced sustained myocardial dysfunction in vivo. We confirmed in a preliminary study that aminoguanidine does not inhibit eNOS function at the dose used. The inhibition by aminoguanidine of NO production was further supported by the marked inhibition of nitrotyrosine formation in the group treated with the inhibitor.

Histological examination showed that the extent of neutrophil infiltration into the myocardium was greater in the IL-1 $\beta$ group than in the control group on day 2. Myocardial MPO activity also was significantly higher in the IL-1 $\beta$ group than in the control group, whereas the activity decreased in the IL-1 $\beta$ group on day 7 . Inflammatory cytokines are known to activate neutrophils, leading to the production of superoxide anions (37). Therefore, activated neutrophils in the myocardium may be one of the potential sources of the production of NO (by iNOS) and superoxide in our model in vivo.

It is known that NO has negative inotropic and chronotropic effects on cardiac myocytes $(38,39)$. Thus, it is conceivable that, in addition to the cardiosuppressive effect of peroxynitrite, those direct negative inotropic effects of NO contributed in part to the development of the sustained myocardial dysfunction in the IL-1 $\beta$ group.

Role of peroxynitrite in the cytokine-induced myocardial dysfunction in vivo. Peroxynitrite is known to be a potent oxidant that could be involved in many pathological processes 
(40). Peroxynitrite may increase $\mathrm{Ca}^{2+}$ influx by disturbing the $\mathrm{Ca}^{2+}$ transport system and impairing functions of myocardial contractile proteins (41), and may inhibit the activity of cellular enzymes such as mitochondrial ATP synthase and aconitase (42).

In this study, the myocardial nitrotyrosine concentrations were significantly higher in the IL- $1 \beta$ group than in the control group on day 2 . The treatment with dexamethasone or aminoguanidine prevented the IL- $1 \beta$-triggered sustained myocardial dysfunction as well as peroxynitrite formation. In addition, a negative linear relationship was noted between the myocardial nitrotyrosine concentrations and LVEF. These results indicate that peroxynitrite plays a substantial role in the cytokine-induced myocardial dysfunction in our canine model in vivo.

It is logical to use a selective peroxynitrite scavenger to examine the role of the radical. However, no such scavenger is available at present because proposed peroxynitrite scavengers, such as uric acid or desferrioxamine, react with hydroxyradical as well $(43,44)$.

Inflammatory cytokine in myocardial stunning after ischemia/reperfusion. The sustained myocardial dysfunction with gradual recovery after application of IL- $1 \beta$ in our model seems to resemble myocardial stunning after ischemia/reperfusion $(10,45,46)$. However, the sustained myocardial dysfunction in the IL-1 $\beta$ group cannot be explained by increased myocardial necrosis or ischemia because the extent of myocardial necrosis (as assessed by CPK-MB) or that of myocardial ischemia (number of MS injected) was comparable between the control and the IL-1 $\beta$ groups. In contrast, the brief dysfunction in the control group may indeed represent the myocardial stunning after myocardial ischemia. The endogenous cytokine network may also be activated after myocardial ischemia/reperfusion, resulting in myocardial damage (47). While superoxide anion has been suggested to be involved in the pathogenesis of myocardial stunning (48), the role of NO remains unclear. It has been shown recently that peroxynitrite (as indicated by the appearance of nitrotyrosine) is, indeed, formed in vivo after cerebral ischemia/reperfusion (24). This study demonstrated that cytokine-triggered formation of NO and the resultant formation of peroxynitrite could cause sustained myocardial dysfunction in vivo, which is distinct from myocardial stunning in its original meaning. The role of endogenous inflammatory cytokines in the pathogenesis of the sustained myocardial dysfunction in our model remains to be elucidated.

Limitations of the study. Several criticisms could be raised in this study. First, embolization technique with IL-1 $\beta$-bound MS was used to locally and selectively deliver the cytokine into the myocardium. Indeed, the intracoronary injection of MS, per se, caused a brief myocardial dysfunction in the control group. However, dexamethasone or aminoguanidine did not alter the time course of LVEF recovery in the control group, suggesting that a mechanism(s) other than NO and peroxynitrite may be involved in the brief myocardial dysfunction in the control group. Second, many endogenous cytokines could be upregulated in our model, and some of them, including endogenous IL-1 and TNF- $\alpha$, could directly impair myocardial contraction (10). However, dexamethasone or aminoguanidine completely prevented the IL- $1 \beta$-triggered myocardial dysfunction, suggesting that the cascade formation of NO (by iNOS) and peroxynitrite, but not the direct negative inotropic effect of endogenous cytokines, may play a central role in the
IL-1 $\beta$-triggered myocardial dysfunction in our model. Third, since LVEF eventually recovered, to some extent, $7 \mathrm{~d}$ after IL-1 $\beta$ administration, the mechanism of the cytokine-triggered myocardial dysfunction in this study cannot explain the potential importance of inflammatory cytokines in the pathogenesis of chronic heart failure. However, in the clinical setting, repeated exposure of inflammatory cytokines may occur, leading to the development of chronic heart failure. In addition, after exposure of inflammatory cytokines, antiinflammatory cytokines, such as TGF- $\beta$ (49), could also be upregulated and inhibit iNOS expression. However, the role of such antiinflammatory cytokines in our model remains to be elucidated.

Clinical implications. This study demonstrated that NO produced by iNOS and the resultant formation of peroxynitrite play a central role in the pathogenesis of cytokineinduced myocardial dysfunction in vivo. Cytokine-induced myocardial damage may occur in a wide variety of cardiovascular diseases, including acute myocarditis $(1,2)$, heart failure $(1,2)$, allograft rejection (3), and coronary reperfusion in acute myocardial infarction $(50,51)$. In these diseases, the strategy to selectively inhibit the iNOS-mediated NO production may be effective to prevent the myocardial damage and the subsequent occurrence of heart failure. In this sense, the development of a safer and more selective inhibitor of iNOS is warranted for the treatment of cytokine-mediated inflammatory cardiovascular diseases.

\section{Acknowledgments}

The authors wish to thank Y. Ohmoto, K. Wada, and M. Ikeda (Otsuka Pharmaceutical Co., Ltd., Tokushima, Japan) for cooperation in this study.

This work was supported in part by grants-in-aid from the Japanese Ministry of Education, Science, Sports, and Culture (Tokyo, Japan) and by a grant-in-aid from the Pfizer Foundation for Cardiovascular Research (Tokyo, Japan).

\section{References}

1. De Belder, A.J., M.W. Radomski, H.J. Why, P.J. Richardson, and J.F. Martin. 1995. Myocardial calcium-independent nitric oxide synthase activity is present in dilated cardiomyopathy, myocarditis, and postpartum cardiomyopathy but not in ischaemic or valvular heart disease. Br. Heart J. 74:426-430.

2. Matsumori, A., T. Yamada, H. Suzuki, Y. Matoba, and S. Sasayama. 1994. Increased circulating cytokines in patients with myocarditis and cardiomyopathy. Br. Heart J. 72:561-566.

3. Yang, X., N. Chowdhury, B. Cai, J. Brett, C. Marboe, R.R. Sciacca, and R.E. Michler. 1994. Induction of myocardial nitric oxide synthase by cardiac allograft rejection. J. Clin. Invest. 94:714-721.

4. Ross, R. 1993. The pathogenesis of atherosclerosis: a perspective for the 1990s. Nature. 362:801-809.

5. Munro, J.M., and R.S. Cotran. 1988. Biology of disease. The pathogenesis of atherosclerosis: atherogenesis and inflammation. Lab. Invest. 58:249-261.

6. Hannson, G.K., L. Jonassan, P.S. Seifert, and S. Stemme. 1989. Immunomechanisms in atherosclerosis. Arteriosclerosis. 9:567-578.

7. Evans, H.G., M.J. Lewis, and A.M. Shah. 1993. Interleukin $1 \beta$ modulates myocardial contraction via dexamethasone-sensitive production of nitric oxide. Cardiovasc. Res. 27:1486-1490.

8. Okusawa, S., J.A. Gelfand, T. Ikejima, R.J. Connolly, and C.A. Dinarello. 1988. Interleukin 1 induces a shock-like state in rabbits. Synergism with tumor necrosis factor and the effect of cyclooxygenase inhibition. J. Clin. Invest. $81: 1162-1172$

9. Shioi, T., A. Matsumori, and S. Sasayama. 1996. Persistent expression of cytokine in the chronic stage of viral myocarditis in mice. Circulation. 94:29302937.

10. Finkel, M.S., C.V. Oddis, T.D. Jacob, S.C. Watkins, B.G. Hattler, and R.L. Simmons. 1992. Negative inotropic effects of cytokines on the heart mediated by nitric oxide. Science. 257:387-389.

11. Levine, B., J. Kalman, L. Mayer, H.M. Fillit, and M. Packer. 1990. Elevated circulating levels of tumor necrosis factor in severe chronic heart failure. 
N. Engl. J. Med. 323:236-241.

12. Torre-Amione, G., S. Kapadia, J. Lee, J.-B. Durand, R.D. Bies, J.B. Young, and D.L. Mann. 1996. Tumor necrosis factor- $\alpha$ and tumor necrosis factor receptors in the failing human heart. Circulation. 93:704-711.

13. Pinsky, M.R., J.-L. Vincent, J. Deviere, M. Alegre, R.J. Kahn, and E. Dupont. 1993. Serum cytokine levels in human septic shock: relation to multiple-system organ failure and mortality. Chest. 103:565-575.

14. Balligand, J.-L., D. Ungureanu-Longrois, W.W. Simmons, D. Pimental, T.A. Malinski, M. Kapturczak, Z. Taha, C.J. Lowenstein, A.J. Davidoff, R.A. Kelly, et al. 1994. Cytokine-inducible nitric oxide synthase (iNOS) expression in cardiac myocytes. J. Biol. Chem. 269:27580-27588.

15. Tsujino, M., Y. Hirata, T. Imai, K. Kanno, S. Eguchi, H. Ito, and F. Marumo. 1994. Induction of nitric oxide synthase gene by interleukin $1 \beta$ in cultured rat cardiocytes. Circulation. 90:375-383.

16. LaPointe, M.C., and J.R. Sitkins. 1996. Mechanisms of interleukin $1 \beta$ regulation of nitric oxide synthase in cardiac myocytes. Hypertension. 27:709-714.

17. Hasan, K., B.-J. Heesen, J.A. Corbett, M.L. McDaniel, K. Chang, W. Allison, B.H. Wolffenbuttel, J.R. Williamson, and R.G. Tilton. 1993. Inhibition of nitric oxide formation by guanidines. Eur. J. Pharmacol. 249:101-106.

18. Misko, T.P., W.M. Moore, T.P. Kasten, G.A. Nickols, J.A. Corbett, R.G. Tilton, M.L. McDaniel, J.R. Williamson, and M.G. Currie. 1993. Selective inhibition of the inducible nitric oxide synthase by aminoguanidine. Eur. J. Pharmacol. 233:119-125.

19. Bradley, P.P., D.A. Priebat, R.D. Christensen, and G. Rothstein. 1982. Measurement of cutaneous inflammation: estimation of neutrophil content with an enzyme marker. J. Invest. Dermatol. 78:206-209.

20. Ohnishi, M., H. Koike, N. Kawamura, S.J. Tojo, M. Hayashi, and S. Morooka. 1996. Role of P-selectin in the early stage of the Arthus reaction. Immunopharmacology. 34:161-170.

21. Huie, R.E., and S. Padmaja. 1993. The reaction of NO with superoxide. Free Radic. Res. Commun. 18:195-199.

22. Beckman, J.S., T.W. Beckman, J. Chen, P.A. Marshall, and B.A. Freeman. 1990. Apparent hydroxyl radical production by peroxynitrite: implications for endothelial injury from nitric oxide and superoxide. Proc. Natl. Acad. Sci. USA. 87:1620-1624

23. Ischiropoulos, H., L. Zhu, and J.S. Beckman. 1992. Peroxynitrite formation from macrophage-derived nitric oxide. Arch. Biochem. Biophys. 298:446-451.

24. Maruyama, W., Y. Hashizume, K. Matsumoto, and M. Naoi. 1996. Identification of 3-nitro-L-tyrosine, a product of nitric oxide and superoxide, as an indicator of oxidative stress in the human brain. J. Chromatogr. B Biomed. Appl. 676:153-158.

25. Tsugita, A., and J.J. Scheffler. 1982. A rapid method for acid hydrolysis of protein with a mixture of trifluoroacetic acid and hydrochloric acid. Eur. J. Biochem. 124:585-588.

26. Petros, A., D. Bennett, and P. Vallance. 1991. Effect of nitric oxide synthase inhibitors on hypotension in patients with septic shock. Lancet. 338:15571558 .

27. Momii, H., H. Shimokawa, J. Oyama, and X.S. Cheng. 1998. Inhibition of adhesion molecules prevents cytokine-induced sustained myocardial dysfunction. J. Mol. Cell. Cardiol. In press. (Abstr.)

28. Cheng, X.S., H. Shimokawa, H. Momii, and J. Oyama. 1997. Role of superoxide anion in the pathogenesis of cytokine-induced myocardial dysfunction in dogs in vivo. Circulation. 96(Suppl.):I605. (Abstr.)

29. Schulz, R., E. Nava, and S. Moncada. 1992. Induction and potential biological relevance of a $\mathrm{Ca}^{+}$-independent nitric oxide synthase in the myocardium. Br. J. Pharmacol. 105:575-580.

30. Rimele, T.J., R.J. Sturm, L.M. Adams, D.E. Henry, R.J. Heaslip, B.M. Weichman, and D. Grimes. 1988. Interaction of neutrophils with vascular smooth muscle: identification of a neutrophil-derived relaxing factor. J. Pharmacol. Exp. Ther. 245:102-111.

31. Lorsbach, R.B., W.J. Murphy, C.J. Lowenstein, S.H. Snyder, and S.W. Russel. 1993. Expression of the nitric oxide synthase gene in mouse macro- phages activated for tumor cell killing. J. Biol. Chem. 268:1908-1913.

32. Shindo, T., U. Ikeda, F. Ohkawa, Y. Kawahara, M. Yokoyama, and K. Shimada. 1995. Nitric oxide synthesis in cardiac myocytes and fibroblasts by inflammatory cytokines. Cardiovasc. Res. 29:813-819.

33. Balligand, J.-L., D. Ungureanu, R.A. Kelly, L. Kobzik, D. Pimental, T. Michel, and T.W. Smith. 1993. Abnormal contractile function due to induction of nitric oxide synthesis in rat cardiac myocytes follows exposure to activated macrophage-conditioned medium. J. Clin. Invest. 91:2314-2319.

34. Brady, A.J.B., P.A. Poole-Wilson, S.E. Harding, and J.B. Warren. 1992 Nitric oxide production with cardiac myocytes reduces their contractility in endotoxemia. Am. J. Physiol. 263:H1963-H1966.

35. Brady, A.J.B., J.B. Warren, P.A. Poole-Wilson, T.J. Williams, and S.E. Harding. 1993. Nitric oxide attenuates cardiac myocyte contraction. Am. J. Physiol. 265:H176-H182.

36. Herbertson, M.J., H.A. Werner, and K.R. Walley. 1996. Nitric oxide synthase inhibition partially prevents decreased LV contractility during endotoxemia. Am. J. Physiol. 270:H1979-H1984.

37. Li, Y., A. Ferrante, and D.P. Harvey. 1996. Neutrophil oxygen radical generation: synergistic responses to tumor necrosis factor and mono/polyunsaturated fatty acids. J. Clin. Invest. 97:1605-1609.

38. Balligand, J.L., R.A. Kelly, P.A. Marsden, T.W. Smith, and T. Michel. 1993. Control of cardiac muscle cell function by an endogenous nitric oxide signaling system. Proc. Natl. Acad. Sci. USA. 90:347-351.

39. Kinugawa, K., O. Kohmoto, A. Yao, T. Serizawa, and T. Takahashi. 1997. Cardiac inducible nitric oxide synthase negatively modulates myocardial function in cultured rat myocytes. Am. J. Physiol. 272:H35-H47.

40. Beckman, J.S., and W.H. Koppenol. 1996. Nitric oxide, superoxide, and peroxynitrite: the good, the bad, and ugly. Am. J. Physiol. 27:C424-C437.

41. Ishida, H., K. Ichimori, Y. Hirota, M. Fukahori, and H. Nakazawa. 1996 Peroxynitrite-induced cardiac myocyte injury. Free Rad. Biol. Med. 20:343-350.

42. Castro, L., M. Rodriguez, and R. Radi. 1994. Aconitase is readily inactivated by peroxynitrite, but not by its precursor, nitric oxide. J. Biol.Chem. 269: 29409-29415.

43. Ames, B.N., R. Catheart, E. Schwiers, and P. Hochstein. 1981. Uric acid provides an antioxidant defense in humans against oxidant- and radical-caused aging and cancer: a hypothesis. Proc. Natl. Acad. Sci. USA. 78:6858-6862.

44. Gutteridge, J.M., R. Richmond, and B. Halliwell. 1979. Inhibition of the iron-catalyzed formation of hydroxyl radicals from superoxide and of lipid peroxidation by desferrioxamine. Biochem. J. 184:469-472.

45. Braunwald, E., and R. Kloner. 1982. The stunned myocardium: prolonged, postischemic ventricular dysfunction. Circulation. 66:1146-1149.

46. Engler, R., and J.W. Covell. 1987. Granulocytes cause reperfusion ventricular dysfunction after 15-minute ischemia in the dog. Circ. Res. 61:20-28.

47. Birdsall, H.H., D.M. Green, J. Trial, K.A. Youker, A.R. Burns, C.R. MacKay, G.J. LaRosa, H.K. Hawkins, C.W. Smith, L.H. Michael, et al. 1997. Complement C5a, TGF- $\beta 1$, and $\mathrm{MCP}-1$, in sequence, induce migration of monocytes into ischemic canine myocardium within the first one to five hours after reperfusion. Circulation. 95:684-692.

48. Myers, M.L., R. Bolli, R.F. Lekich, C.J. Hartley, and R. Roberts. 1985. Enhancement of recovery of myocardial function by oxygen free-radical scavengers after reversible regional ischemia. Circulation. 72:915-921.

49. Roberts, A.B., Y. Vodovotz, N.S. Roche, M.B. Sporn, and C.F. Nathan. 1992. Role of nitric oxide in antagonistic effects of transforming growth factor- $\beta$ and interleukin $1 \beta$ on the beating rate of cultured cardiac myocytes. Mol. Endocrinol. 6:1921-1930.

50. Guillen, I., M. Blanes, and J.V. Castell. 1995. Cytokine signaling during myocardial infarction: sequential appearance of IL-1 beta and IL-6. Am. J. Physiol. 269:R229-R235.

51. Tashiro, H., H. Shimokawa, K. Yamamoto, M. Nagano, M. Momohara, K. Muramatsu, and A. Takeshita. 1995. Monocyte-related cytokines in acute myocardial infarction. Am. Heart J. 130:446-452. 